\title{
CONCURSO NEGRO E EDUCAÇÃO: AÇÃO AFIRMATIVA DE FORMAÇÃO DE PESQUISADORES/AS NO BRASIL
}

\author{
Tatiane Cosentino Rodrigues ${ }^{1}$ \\ JoAna CÉlia dos Passos ${ }^{2}$
}

Flávia FrancChini ${ }^{3}$

\begin{abstract}
RESUMO: O artigo analisa os impactos do Concurso Negro e Educação, que fomentou a pesquisa sobre educação e relações étnico-raciais no Brasil no período de 1999 a 2007. Para isso, fez-se um levantamento dos(as) egressos(as), a fim de identificar seus espaços de atuação, suas inserções como pesquisadores(as) e suas participações na produção acadêmica relativa às questões raciais. Além disso, observaram-se também a mobilidade acadêmica e as redes que integram. O exercício evidenciou a importância desse programa de ação afirmativa para a inserção acadêmica dos(as) participantes e na ampliação dos estudos do campo das relações raciais no Brasil. Como principal fonte, foram analisados os currículos dos(as) participantes egressos(as) disponíveis na plataforma do $\mathrm{CNPq}$, bem como os relatórios de avaliação do programa.
\end{abstract}

Palavras-chave: Concurso Negro e Educação. Ação afirmativa. Pesquisa em educação. Educação e relações étnico-raciais.

\section{CONCURSO NEGRO E EDUCAÇÃO: AFFIRMATIVE ACTION FOR THE TRAINING OF RESEARCHERS IN BRAZIL}

ABSTRACT: The article analyzes the impacts of Concurso Negro e Educação, that fostered research on education and ethnic-racial relations in Brazil from 1999 to 2007. For this, a survey of graduates was carried out in order to identify their areas of action, their insertions as researchers, and their participation in academic production related to racial issues. In addition, academic mobility and the networks they integrate were also observed. The exercise highlighted the importance of this affirmative action program for the academic insertion of the participants, and for the expansion of studies in the field of race relations in Brazil. As the main source, the curricula of the egress participants available on the $\mathrm{CNPq}$ platform and the program evaluation reports were analyzed.

Keywords: Concurso Negro e Educação. Affirmative action. Education research. Education and ethnic-racial relations.

\footnotetext{
1.Universidade Federal de São Carlos - Departamento de Teorias e Práticas Pedagógicas - Programa de Pós-graduação em Educação - São Carlos (SP), Brasil. E-mail: tatiane.rodrigues@ufscar.br

2.Universidade Federal de Santa Catarina - Centro de Ciências da Educação - Departamento de Estudos Especializados em Educação - Florianópolis (SC), Brasil. E-mail: passos.jc@gmail.com

3.Universidade Federal de São Carlos - Centro de Educação e Ciências Humanas - Programa de Pós-graduação em Educação - São Carlos (SP), Brasil. E-mail: flavia.francchini@gmail.com

Editor de Seção: Salomão Barros Ximenes

Editores convidados: Nilma Lino Gomes, José Eustáquio Brito e Paulo Vinicius Baptista da Silva
} 


\section{CONCURSO NEGRO E EDUCAÇÃO: ACCIÓN AFIRMATIVA PARA LA FORMACIÓN DE INVESTIGADORES EN BRASIL}

RESUMEN: El artículo analiza los impactos del Concurso Negro e Educação, que fomentó la investigación acerca de educación y relaciones étnico-raciales en Brasil en el periodo de 1999 a 2007. Para tanto, se realizó un levantamiento respecto de los(as) egresados(as), a fin de identificar sus espacios de actuación, sus inserciones como investigadores(as) y sus participaciones en la producción académica relativa a las cuestiones raciales. Además, se observó también la movilidad académica y las redes que integran. El ejercicio evidenció la importancia de este programa de acción afirmativa para la inserción académica de los(as) participantes y la expansión de los estudios del campo de las relaciones raciales en Brasil. Como principal fuente, fueron analizados los currículos de los(as) participantes egresados(as), disponibles en la plataforma del Consejo Nacional de Desarrollo Científico y Tecnológico (CNPq), y los informes de evaluación del Programa.

Palabras-clave: Concurso Negro e Educação. Acción afirmativa. Investigación en educación. Educación y relaciones étnico-raciales.

\section{Introdução}

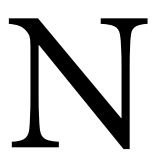

o Brasil, o campo de estudos sobre relações étnico-raciais ganhou maior destaque a partir dos anos 1990, como resultado também da pressão do movimento negro. É nesse período que as pesquisas acadêmicas e estatais passam a considerar as questões raciais como dimensão de análise juntamente com os aspectos socioeconômicos. Pauta histórica e permanente das lutas do movimento negro, que sempre compreendeu a importância da escolarização em todos os níveis para a população negra, a educação é uma das áreas que mais adere a essa perspectiva.

Num sentido macro, nesse período observamos uma crescente intervenção de organismos internacionais em questões relativas à diversidade. O reconhecimento da diversidade cultural passou a ser objeto de informes e resoluções de organismos como a Organização das Nações Unidas para a Educação, a Ciência e a Cultura (UNESCO) e ganhou múltiplas expressões ao longo da caminhada dessa organização. Na década de 1990, a diversidade é trabalhada no relatório da Comissão Mundial de Cultura e Desenvolvimento, no documento denominado "Nossa diversidade criadora".

Ao longo da nossa história, intelectuais negras e negros ${ }^{1}$ contribuíram e contribuem com o desenvolvimento de um pensamento negro em educação, sobretudo a partir de suas inserções como docentes em universidades brasileiras a partir dos anos 1980. Esses(as) vão se caracterizar, como denominado por Santos, por uma "ética da convicção antirracismo" e um "ethos acadêmico-científico ativo" (2011), cujo perfil é resultado da participação e/ou de diálogo em/com movimentos negros nas experiências sociais, nas periferias, na prática cotidiana e na constituição intelectual de negros(as) que não tiveram a devida legitimidade e o reconhecimento pela ciência moderna ocidental.

São intelectuais negras e negros que, ao produzirem conhecimentos, articulam-nos às vivências da população negra e às desigualdades que a assolam; "indagam o lugar ocupado pelo outro, pelo diferente e pelas diferenças na produção acadêmica" (GOMES, 2010); interpelam o racismo estrutural e tensionam o racismo acadêmico a partir de seus campos de atuação. Suas produções problematizam a estrutura colonial que marca a hegemonia do cânone acadêmico ainda nos dias de hoje. Em síntese, a atuação desses(as) intelectuais negros(as) se dá dentro da ciência, articulada com as lutas sociais do 
povo negro (GOMES, 2010). Embora referindo sua própria história, bell hooks (1995) sintetiza em grande medida a atuação de ampla maioria da intelectualidade negra quando afirma: "a vida intelectual não precisa levar-nos a separar-nos da comunidade, mas antes pode capacitar-nos a participar mais plenamente da vida da família e da comunidade" (HOOKS, 1995, p. 466).

Ao problematizar a produção do conhecimento considerado universal, os(as) intelectuais sustentam-se em pesquisas articuladas com diferentes movimentos sociais, questionando e rompendo as amarras da produção científica eurocêntrica. Essa perspectiva chama a atenção das Ciências Humanas e Sociais no sentido de incorporar em suas análises outras dimensões que integrem o contexto social brasileiro, reconhecendo desigualdades raciais e de gênero (GAUDIO, 2021, p. 129). Com isso, inaugura-se, nas universidades, uma nova agenda de pesquisas, tendo intelectuais negros(as) como investigadores(as) das questões raciais. Se até então eram considerados(as) somente objeto de estudo, passaram a ser produtores(as) de conhecimentos. Suas pesquisas e estudos, acrescidos das ações efetuadas pelo movimento negro, revelaram desigualdades nos âmbitos econômico, educacional, da saúde, da segurança e da habitação, tornando a discussão racial uma pauta política.

As tentativas de inferiorização da produção de conhecimento formulada por intelectuais negros(as) é materializada nos espaços universitários idealizados por uma tradição teórica brancocentrada. Tendo como referência os estudos de Boaventura Sousa Santos, "para quem o epistemicídio se constituiu e se constitui num dos instrumentos mais eficazes e duradouros da dominação étnica/racial”, Carneiro nos ensina que:

[...] o epistemicídio é, para além da anulação e desqualificação do conhecimento dos povos subjugados, um processo persistente de produção da indigência cultural: pela negação ao acesso à educação, sobretudo de qualidade; pela produção da inferiorização intelectual; pelos diferentes mecanismos de deslegitimação do negro como portador e produtor de conhecimento e de rebaixamento da capacidade cognitiva pela carência material e/ou pelo comprometimento da auto-estima [sic] pelos processos de discriminação correntes no processo educativo (2005, p. 97).

Marilena Chauí (2001), filósofa brasileira, e Boaventura de Sousa Santos (2004) chamam a atenção para a necessidade de a universidade do século XXI se pautar pela pluriversidade. Nesse sentido, é preciso que as instituições sejam capazes de acolher experiências, expressões, conhecimentos e epistemologias outras que não tenham como referência o modelo eurocêntrico da ciência moderna. Se for assim, a pluriversidade ou universidade não poderá mais silenciar sobre o racismo estrutural e institucional também no meio acadêmico.

O racismo epistêmico explicita a hierarquia entre os conhecimentos considerados válidos e legítimos de serem ensinados. Grosfoguel (2016) alerta para as estruturas hegemônicas do conhecimento, sobretudo nas Ciências Sociais, conservadas sob o privilégio epistêmico produzido especialmente por homens brancos de cinco países: Alemanha, França, Itália, Inglaterra e Estados Unidos. O pensamento hegemônico define que o conhecimento produzido por homens desses países apresenta uma capacidade universal de análise de distintas realidades sócio-históricas. Para Figueiredo e Grosfoguel,

[a] perspectiva particular do homem branco se ergue como a norma universal de produção de conhecimentos, por meio da qual se medem e avaliam todas as outras formas de produzir conhecimentos. O homem branco pensa desde uma geopolítica e corpo-política do conhecimento particular, como homem, branco e privilegiado; porém, em nome de 
um suposto universalismo, encobre sua localização, recorrendo ao mito que lhe permite pensar fora do corpo e fora do tempo e do espaço (2009, p. 228).

Nesse cenário, busca-se descolonizar as ciências, retomando visões de mundo, conteúdos e metodologias de que a ciência ocidental se apropriou e acumulou, a partir dos quais criou seus próprios conteúdos e metodologias, deixando de mencionar suas origens. São pouco difundidas as bases africanas, árabes, chinesas, dos povos originários, entre outras, a partir das quais foram gerados os fundamentos das ciências e filosofias atuais (SILVA, 2003, p. 49). Silva (2003) sublinha que a universidade como espaço intelectual, científico, educativo e político não poderá continuar se sustentando por muito tempo dessa maneira se se mantiver distante e desinteressada das questões que dizem respeito aos direitos humanos, ao diálogo entre culturas, aos direitos dos povos (SILVA, 2003, p. 45).

Esse desafio epistêmico é uma das principais dimensões das políticas de ação afirmativa, ${ }^{2}$ que não se reduzem apenas ao acesso a determinados espaços, mas visam também à produção de mudanças e a ampliações dos referenciais científicos.

O Concurso Negro e Educação (1999-2007) se originou de um esforço conjunto de intelectuais negros(as) e brancos(as), da Associação Nacional de Pós-Graduação e Pesquisa em Educação (ANPEd), da Ação Educativa e da Fundação Ford. Inscreve-se no âmbito das ações afirmativas com foco na formação de pesquisadores(as) iniciantes na temática educação e relações étnico-raciais.

Muitos(as) desses(as) intelectuais também criaram, em meados dos anos 1990, os primeiros Núcleos de Estudos Afro-brasileiros $(\mathrm{NEAB})^{3}$ e, na década seguinte, construíram a Associação Brasileira de Pesquisadores Negros e Negras (ABPN), "uma associação civil, sem fins lucrativos, filantrópica, assistencial, cultural, científica e independente", tendo como finalidade "o ensino, pesquisa e extensão acadêmico-científica sobre temas de interesse das populações negras do Brasil”. ${ }^{4}$

Tais iniciativas nos levam a ressaltar o papel protagonista e militante de intelectuais negros(as) que não somente produzem conhecimentos, mas constroem espaços outros de atuação e articulação acadêmica, capazes de promover a inserção e a formação de novas gerações de outros(as) intelectuais negros(as).

\section{O Concurso Negro e Educação}

O Concurso Negro e Educação foi realizado entre os anos 1999 e 2007, teve quatro edições e resultou de uma "provocação feita pela Fundação Ford ${ }^{5}$ à ANPEd", 6 conforme o documento "Avaliação Concurso Negro e Educação”, elaborado por José Geraldo da Rocha e Andrea Couto (2007). A professora Maria Malta, em entrevista aos autores, relata que o concurso

[...] foi criado através de uma interação entre a ANPEd, a Fundação Ford e a Ação Educativa. ${ }^{7}$ Eram esses três protagonistas. Participaram das conversas iniciais para a criação do Concurso o Nigel Brooke, [...], da Fundação Ford [...], o Sérgio Haddad, que também fazia parte da diretoria da ANPEd, mas que estava como diretor da Ação Educativa, e eu, que na época era presidente da ANPEd [...]. O Nigel já tinha um diagnóstico dele, [...] ele achava que seria nessa questão das relações raciais. Na ANPEd, por outro lado, havia um diagnóstico um pouco diferente, [...] achava que era mais na área de Diversidade Cultural, Direitos Humanos, englobava a questão do negro, mas não só (MALTA apud ROCHA; COUTO, 2007). 
Percebe-se que, embora não tenha sido inicialmente concebido pela ANPEd como um projeto com o foco exclusivo na formação de pesquisadores(as) negros(as), é nesse público que o concurso se assenta, como fica explicitado em seus objetivos:

- Ampliar o quadro de pesquisadores da área negro e educação por meio da formação de pesquisadores iniciantes.

- Ampliar o conhecimento sobre as temáticas relativas ao negro e educação.

- Propiciar a ampliação e a discussão de referências teóricas e metodológicas pertinentes à temática negro e educação.

- Contribuir para a consolidação de uma comunidade de pesquisadores interessados no tema (ROCHA; COUTO, 2007, p. 10).

Assim, o concurso foi organizado a partir de dotação (bolsas) como incentivo à produção de conhecimentos sobre educação e relações raciais, além de um processo formativo desenvolvido a partir de atividades como seminários específicos para discussão das pesquisas, da metodologia e do referencial teórico, com proeminentes pesquisadores(as) no campo das relações raciais. O desenvolvimento das pesquisas era apresentado em pôsteres nas reuniões da ANPEd.

Nas quatro edições, o concurso formou 61 pesquisadores(as) oriundos(as) de todas as regiões brasileiras. Contudo, o número de inscritos(as) foi sempre além das condições de acolhida, como se pode observar abaixo:

Tabela 1. Número de projetos inscritos e selecionados

\begin{tabular}{ccc}
\hline Edição/ano & Total de propostas recebidas & Total de propostas aprovadas \\
\hline Primeira/1999 & 171 & 10 \\
\hline Segunda/2001 & 40 & 15 \\
\hline Terceira/2003 & 216 & 20 \\
\hline Quarta/2005 & 219 & 16 \\
\hline TOTAL & 647 & 61 \\
\hline
\end{tabular}

Fonte: Rocha e Couto (2007).

Nota-se, a partir das informações da Tabela 1, que a demanda apresentada foi muito superior à capacidade de acolhida pelo Concurso Negro e Educação. Apenas 9\% dos(as) inscritos(as) tiveram os projetos selecionados. A seleção dos projetos de pesquisa se orientou por critérios acadêmicos e pela equidade de gênero e região.

Observando o perfil traçado por Rocha e Couto (2007), percebe-se que 68\% dos selecionados eram negros/(as) e 62\% tinham entre 31 e 50 anos. As mulheres representaram $75 \%$ do total de bolsistas, o que se justifica por o campo educacional ser majoritariamente feminino. Essa é também uma tendência identificada por Rosemberg e Andrade (2008) na análise sobre a composição étnico-racial e de gênero do programa de bolsas da Fundação Ford. ${ }^{8}$ Segundo os autores, o fato de mulheres terem indicadores educacionais melhores que os dos homens é uma realidade no Brasil desde a década de 1950 e, por isso, esse dado deveria ser observado na discussão sobre as políticas de ação afirmativa.

As temáticas de pesquisa dos(as) bolsistas tiveram como principais focos ensino e práticas educacionais, identidade e autoestima, cultura e patrimônio, ações afirmativas e desigualdades (ROCHA; COUTO, 2007). Fica evidente o amplo leque de estudos realizados, o que contribui para o fortalecimento do campo das relações raciais. As pesquisas desenvolvidas pelos(as) bolsistas resultaram em quatro publicações: 
1a edição - "Negro e educação: presença do negro no sistema educacional brasileiro"; $2^{a}$ edição - "Identidade Negra: pesquisas sobre o negro e a educação no Brasil"; 3ㄹ edição - "Negro e Educação: escola, identidades, cultura e políticas públicas"; e $4^{\mathrm{a}}$ edição - "Linguagens, resistências e políticas públicas".

Rocha e Couto (2007), ao analisarem o impacto do Concurso Negro e Educação, identificaram que a iniciativa proporcionou reconhecimento acadêmico a $84 \% \operatorname{dos}($ as) participantes, além de indicar promoção de visibilidade e de notoriedade das temáticas pelo fomento realizado pelos(as) egressos(as).

Os relatórios de avaliação de 2004 e 2007 enfatizam a importância do Concurso Negro e Educação, seja para a formação de novos(as) pesquisadores(as), seja para a ampliação e o fortalecimento do campo de estudos das relações raciais.

Os vários títulos trabalhados pelos pesquisadores vão garantir uma maior visibilidade da temática no universo acadêmico à luz de um compromisso identitário, bem como auferir reconhecimento aos novos sujeitos a partir de seus trabalhos no Concurso Negro e Educação. Isso faz com que não apenas se reconheça as lacunas existentes, provocadas pela ausência deste conhecimento sistematizado na área da educação, mas, também, a aceitação do desafio de suprir esta lacuna como uma exigência do processo de formação e produção do conhecimento perpassando as relações raciais. Além disto, está se construindo um grupo de referência nacional na abordagem do tema negro e educação. Consequentemente, os resultados desses trabalhos servem como subsídios às reflexões e debates numa perspectiva de combate ao racismo no processo educacional e na vida social brasileira. Os pesquisadores negros demonstraram com seus trabalhos que sabem fazer, e tendo oportunidade de fazê-lo, o fizeram bem. Nisto reside uma significativa contribuição do Concurso Negro e Educação: oportunidades para produção e socialização do saber à luz da temática afro-brasileira na educação (ROCHA; COUTO, 2007, p. 23).

O Concurso, de toda a forma, teria contribuído para a ampliação do espaço ocupado por essa temática no meio acadêmico: Eu acho que esse é um lugar importante para o começo desse tipo de preocupação dentro dos lugares acadêmicos... Eu acho que a própria existência do Concurso e em seguida a formação do GT na ANPEd contribuíram para que pessoas se sentissem mais autorizadas a apresentar determinados projetos para financiamento em outros lugares. Sem dúvida esse espaço foi o único no momento em que foi criado (DI PIERRO et al., 2004, p. 15).

Para a maioria dos(as) bolsistas e orientadores(as), o concurso também cobriu uma lacuna das agências que fomentam pesquisa, pois "os estudos não seriam desenvolvidos sem as bolsas concedidas por esta iniciativa", haja vista que "a singularidade do Concurso reside no apoio a graduandos, a pessoas que não têm vínculos com a pós-graduação e que se encontram com idade mais avançada, que não recebem apoio do sistema convencional de fomento à pesquisa". Além disso, "o tema do Concurso também é marginal na academia, o que dificulta ainda mais ter acesso ao sistema de fomento" (DI PIERRO et al., 2004, p. 36).

No relatório, Rocha e Couto destacam o impacto do concurso nas organizações promotoras, como se pode observar a seguir:

- Modificação sobre a percepção da presença negra e reflexão sobre a questão racial na academia e, principalmente, na própria ANPEd;

- Abertura para a questão racial em alguns orientadores na ANPEd;

- Consolidação da discussão sobre a questão racial na ANPEd; e 
- Mudança de lugar social da Ação Educativa: passa de um olhar das análises que se faz das pesquisas e da produção do conhecimento a uma atitude investigativa (2007, p. 41-42).

Percebe-se que as organizações passaram por um processo pedagógico que as permitiu assumirem a questão racial como parte de suas ações e estratégias. Sérgio Haddad assim se manifesta: "Eu acho que quem mais ganhou com isso foi a ANPEd, criou um núcleo de preocupação, um grupo de estudos, um GT. Aglutinou pesquisadores e pautou o tema" (apud ROCHA; COUTO, 2007, p. 42). Em relação à Ação Educativa, instituição sob sua coordenação, ele afirma "uma certa mudança no olhar das análises que se fazem das pesquisas e da produção de conhecimento [...]", passa "a uma atitude em relação a investigar de que maneira a temática está sendo incorporada no Sistema Público de Ensino" (apud ROCHA; COUTO, 2007, p. 42). O processo pedagógico sobre as relações raciais no Brasil, vivenciado tanto pela ANPEd como pela Ação Educativa, tem repercussão após todos esses anos.

Fica evidente que as questões raciais vão estar mais presentes na ANPEd, por meio de pesquisadores(as) negros(as) que, em 2001, no ensejo do Negros e Educação, criaram o GT 21. Com isso, há uma presença maior de negros(as) nas reuniões da ANPEd, com maior visibilidade para as temáticas de pesquisa oriundas desse campo de estudos.

\section{Análises dos Currículos Lattes dos(as) Egressos(as)}

Em 2015, realizamos um primeiro ${ }^{9}$ levantamento de informações dos(as) egressos(as) das quatro edições do Concurso Negro e Educação. Esse levantamento foi feito a partir de uma consulta aos relatórios de avaliação do programa e aos currículos disponibilizados pelos(as) pesquisadores(as) na plataforma Lattes ${ }^{10}$ do CNPq.

Em 2021, ${ }^{11}$ retomamos o mapeamento das informações dos(as) egressos(as) na mesma plataforma. Nas quatro edições realizadas, o concurso contemplou 61 projetos de pesquisa de 60 pesquisadores(as), considerando que uma pesquisadora participou de duas edições. Na consulta à plataforma do CNPq, localizamos 56 currículos, o que corresponde a 93\% dos(as) participantes que compõem nossa amostra. Desse total, oito currículos não são atualizados há mais de cinco anos e 48 currículos foram atualizados nos últimos anos, o que representa $80 \%$ dos(as) egressos(as) do programa.

Extraímos desses currículos as informações de temas pesquisados, instituições de atuação profissional dos(as) egressos(as), atividades profissionais, número de trabalhos orientados e formação de redes internacionais de pesquisa.

Esse primeiro trabalho, restrito à análise dos currículos, será posteriormente complementado com uma fase qualitativa com os(as) egressos(as). O currículo da Plataforma Lattes é uma ferramenta importante utilizada pelas agências brasileiras de fomento à pesquisa e por isso se consolida como um instrumento de análise do perfil e da trajetória acadêmica de pesquisadores(as) brasileiros(as) em atividade, mas não esgota um mapeamento mais detalhado das trajetórias dos(as) egressos(as).

\section{Os(as) Egressos(as) do Concurso Negro e Educação}

A vinculação institucional e/ou profissional dos(as) egressos(as) é um importante indicador do impacto do concurso como uma política de ação afirmativa. Uma parte significativa atua em Instituições de 
Ensino Superior (IES). Esse resultado também pode estar relacionado ao processo de expansão do Ensino Superior público a partir de 2004, com a ampliação no número de vagas nas universidades e a criação de novas instituições e campi no interior do país. Durante o Programa de Apoio a Planos de Reestruturação e Expansão das Universidades Federais (Reuni), entre 2005 e 2017, foram criadas dezoito universidades federais no Brasil.

A sistematização dos dados a partir das informações disponibilizadas no Currículo Lattes demonstra que $47(83 \%)^{12}$ egressos(as) informaram as suas vinculações institucionais. A partir dos resultados, é possível observar que a atual distribuição dos(as) egressos(as) contempla as quatro regiões do país, dezoito estados, 32 universidades e institutos federais de educação, ciência e tecnologia públicos, duas IES privadas e quatro vinculações a governos estaduais e municipais.

A Tabela 2 relaciona os vínculos institucionais por região, estado, instituição e número de egressos(as) nessas instituições. Em alguns casos, é possível verificar a presença de dois(duas) ou três egressos(as) na mesma instituição, a exemplo da Universidade da Integração Internacional da Lusofonia Afrobrasileira (UNILAB) e Universidade do Estado da Bahia (Uneb).

A distribuição regional dos(as) egressos(as) sugere que o critério regional no desenho das edições do Concurso Negro e Educação foi importante e repercutiu numa distribuição regional de atuação profissional. É possível identificar ainda uma concentração nas regiões Nordeste e Sudeste.

O mesmo se aplica ao recorte de gênero. Das 47 vinculações profissionais elencadas na Tabela 2, 34 (72\%) são de mulheres e, em sua quase totalidade, de mulheres autodeclaradas negras (pretas e pardas).

Outro importante indicador do impacto e dos resultados refere-se ao número de trabalhos orientados pelos(as) egressos(as). Agrupamos os números informados de orientações de trabalho de conclusão de curso, iniciação científica, mestrado, doutorado e especialização (Tabela 3). O registro contemplou as orientações em andamento (A) e concluídas (C), bem como as informações contidas no quesito "outras formas de orientação".

Inicialmente, é possível observar que os(as) egressos(as) já reúnem um número expressivo de orientações concluídas em todos os níveis, destacando-se os números de orientação de trabalhos de conclusão de curso e especialização. Os dois números expressam um perfil de orientação de forte atuação na formação inicial e na formação continuada.

O crescente número de trabalhos de mestrado e doutorado expressa a trajetória desses(as) pesquisadores(as) no ingresso nos programas de pós-graduação, na conclusão de orientações de mestrado e o posterior ingresso nas orientações de doutorado. Outro fator importante para a compreensão dessa trajetória é a própria existência de programas de pós-graduação com mestrado e doutorado nas instituições relacionadas.

De forma geral, os números totais expressam como os(as) egressos(as) do concurso estão formando, em diferentes níveis, novas gerações de pesquisadores(as) na temática étnico-racial e educação.

No interior da temática geral de educação e relações étnico-raciais, a partir das informações contidas no campo do currículo "temas pesquisados", observamos uma diversidade de temáticas, que compreendem todos os níveis e modalidades de ensino e ampliam o próprio escopo de temáticas relacionadas durante as edições do concurso. Na Tabela 4, estão relacionados os temas pesquisados, como informado nos currículos. Além da amplitude dos temas relacionados, verifica-se a conexão entre as temáticas e os principais desafios contemporâneos de enfrentamento ao racismo. 
Tabela 2. Vinculações institucionais dos(as) egressos(as) por instituições e regiões do país

\begin{tabular}{|c|c|c|c|c|}
\hline Região & UF & Instituição & Sigla & Número \\
\hline \multirow{5}{*}{ Norte } & $\mathrm{PA}$ & Universidade Federal do Sul e Sudeste do Pará & UNIFESSPA & 1 \\
\hline & PA & Universidade Federal do Pará & UFPA & 2 \\
\hline & TO & Universidade Federal de Tocantins & UFT & 1 \\
\hline & AP & Universidade Federal do Amapá & UNIFAP & 1 \\
\hline & $\mathrm{AP}$ & Centro de Ensino Superior do Amapá & CEAP & 1 \\
\hline \multirow{11}{*}{ Nordeste } & $\mathrm{BA}$ & Universidade Federal da Bahia & UFBA & 1 \\
\hline & $\mathrm{BA}$ & Universidade do Estado da Bahia & Uneb & 3 \\
\hline & $\mathrm{BA}$ & Universidade Federal do Recôncavo da Bahia & UFRB & 1 \\
\hline & BA & Instituto Federal da Bahia & IFBA & 1 \\
\hline & $\mathrm{CE}$ & Universidade Estadual do Ceará & UECE & 1 \\
\hline & PI & Universidade Federal do Piauí & UFPI & 1 \\
\hline & $\mathrm{CE}$ & $\begin{array}{c}\text { Universidade da Integração Internacional da Lusofonia } \\
\text { Afrobrasileira }\end{array}$ & UNILAB & 3 \\
\hline & $\mathrm{PE}$ & Universidade de Pernambuco & UPE & 1 \\
\hline & $\mathrm{CE}$ & Universidade Federal de Sergipe & UFS & 1 \\
\hline & $\mathrm{CE}$ & Governo do Estado de Sergipe & & 1 \\
\hline & $\mathrm{RN}$ & Universidade Federal do Rio Grande do Norte & UFRN & 1 \\
\hline \multirow{3}{*}{ Centro-Oeste } & $\mathrm{GO}$ & Universidade Estadual de Goiás & UEG & 1 \\
\hline & DF & Universidade de Brasília & UnB & 2 \\
\hline & MS & Universidade Federal do Mato Grosso do Sul & UFMS & 1 \\
\hline \multirow{4}{*}{ Sul } & PR & Universidade Estadual do Oeste do Paraná & UNIOESTE & 2 \\
\hline & PR & Universidade estadual de Ponta Grossa & UEPG & 1 \\
\hline & SC & Universidade Federal de Santa Catarina & UFSC & 1 \\
\hline & RS & Governo do Estado do Rio Grande do Sul & & 1 \\
\hline \multirow{14}{*}{ Sudeste } & RJ & Universidade Federal Fluminense & UFF & 2 \\
\hline & RJ & Universidade Federal do Estado do Rio de Janeiro & Unirio & 1 \\
\hline & $\mathrm{RJ}$ & Universidade do Estado do Rio de Janeiro & Uerj & 1 \\
\hline & $\mathrm{RJ}$ & Centro Federal de Educação Tecnológica & CEFET-RJ & 1 \\
\hline & $\mathrm{RJ}$ & Universidade Federal Rural do Rio de Janeiro & UFRRJ & 1 \\
\hline & SP & Universidade Católica de Campinas & PUC-Campinas & 1 \\
\hline & SP & Universidade Federal de São Carlos & UFSCar & 1 \\
\hline & SP & Universidade Cidade de São Paulo & UNICID & 1 \\
\hline & SP & Centro Estadual de Educação Tecnológica Paula Souza & CPS & 1 \\
\hline & SP & Secretaria Municipal de Educação & SME & 1 \\
\hline & MG & Universidade Federal de Ouro Preto & UFOP & 2 \\
\hline & MG & Escola Municipal Florestan Fernandes (SP) & & 1 \\
\hline & MG & Universidade Federal de Minas Gerais & UFMG & 1 \\
\hline & MG & Universidade Federal de Alfenas & UNIFAL & 1 \\
\hline
\end{tabular}

Fonte: Elaboração própria, 2021. 


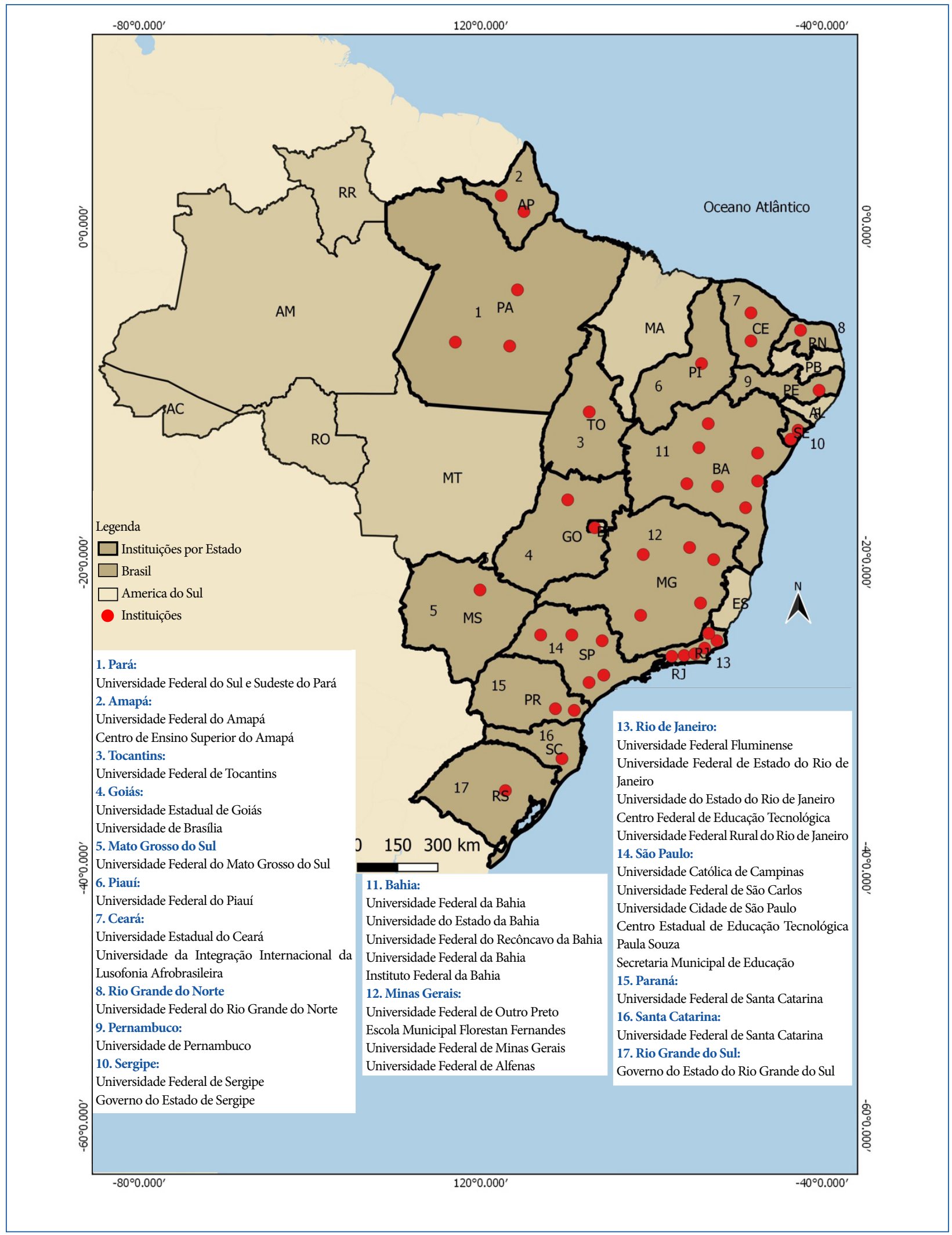

Fonte: Elaboração própria, 2021

Figura 1. Mapa de geolocalização dos(as) egressos(as) do Concurso Negro e Educação - Base Lattes 
Tabela 3. Trabalhos em andamento e concluídos orientados por egressos(as) do Concurso Negro e Educação

\begin{tabular}{ccccccccccc}
\hline \multirow{2}{*}{ Edições } & \multicolumn{2}{c}{ TCC } & \multicolumn{2}{c}{ IC } & \multicolumn{2}{c}{ Mestrado } & \multicolumn{2}{c}{ Doutorado } & \multirow{2}{*}{ Espec. } & \multirow{2}{*}{ Outras } \\
\cline { 2 - 10 } & A & C & A & C & A & C & A & C & \\
\hline 1o CNE & 6 & 164 & 21 & 17 & 11 & 6 & 1 & - & 36 & 7 \\
\hline 2o CNE & 37 & 299 & 25 & 98 & 41 & 94 & 10 & 9 & 159 & 97 \\
\hline 3o CNE & 6 & 140 & 4 & 51 & 14 & 44 & 10 & 3 & 83 & 22 \\
\hline 4o CNE & 2 & 106 & 4 & 39 & 6 & 32 & 4 & - & 54 & 32 \\
\hline Total & 51 & 709 & 54 & 205 & 72 & 176 & 25 & 12 & 332 & 158 \\
\hline
\end{tabular}

Fonte: Elaboração própria, 2021.

Tabela 4. Relação de temas pesquisados segundo informações do Currículo Lattes

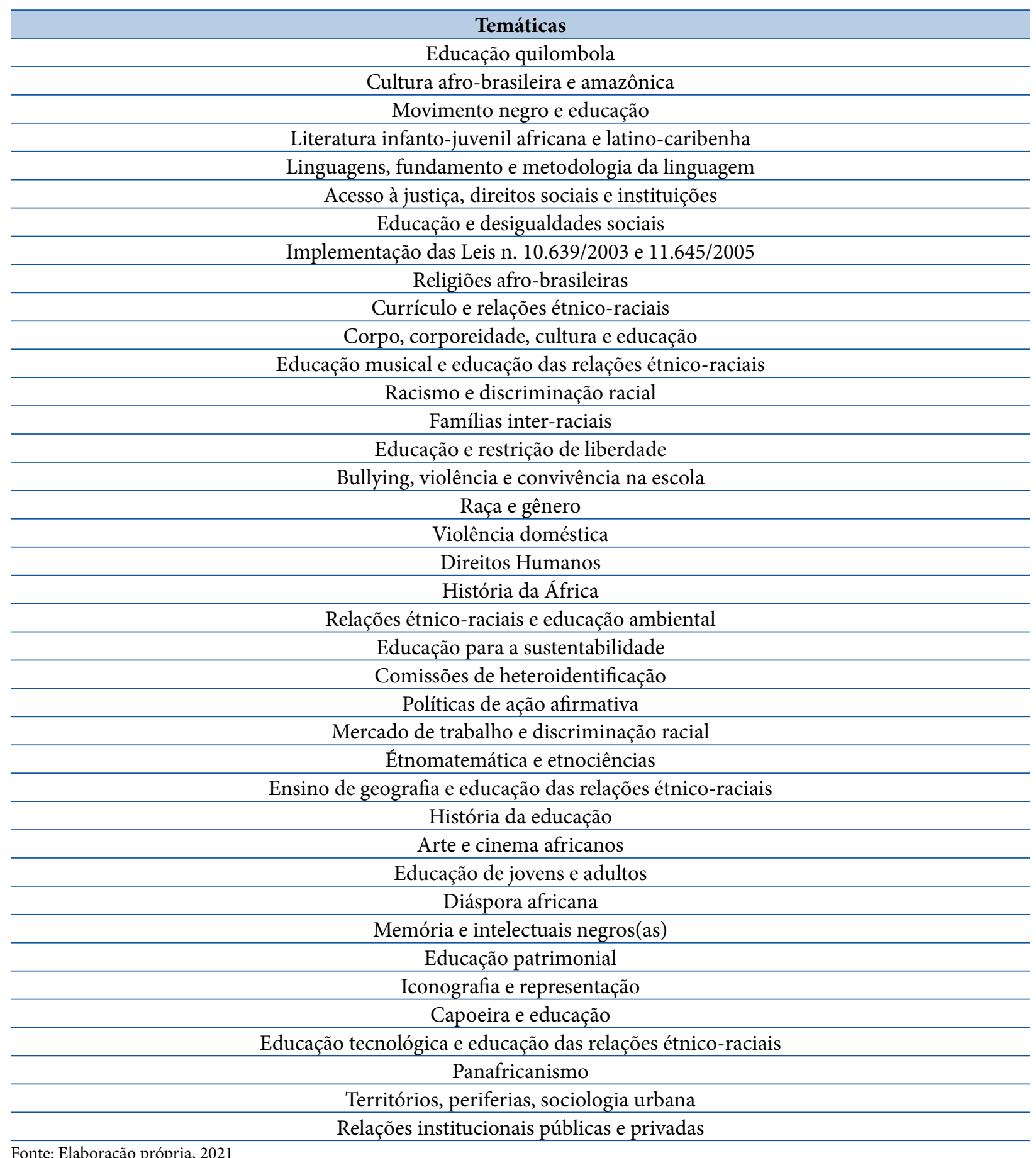


Além da rede de formação inicial e continuada construída pelo coletivo dos(as) egressos(as), é possível observar e relacionar que esse coletivo também tem ocupado espaços decisórios na gestão de instituições de ensino, mas também nos governos estaduais e municipais. Nas IES, centros de educação tecnológica e secretarias de educação estaduais e municipais, a atuação é relacionada à atuação em espaços de gestão, coordenação e formação continuada. Dezoito (32\%) egressos(as) registraram em seus currículos um período de atuação nessas atividades, nos últimos anos, enquanto 20 (35\%) registraram como atividade em curso. As principais atividades são atuação nos NEAB e/ou grupos correlatos, coordenações de curso e estágio do Programa Institucional de Bolsas de Iniciação à Docência (PIBID), coordenação e vice-coordenação de programas de pós-graduação e de mestrados acadêmicos, profissionais e interdisciplinares. Nota-se também um número de egressos(as) que foram ou são diretores de unidades acadêmicas, departamentos e/ou centros de educação, diretorias e/ou pró-reitorias de extensão.

Há uma forte participação também nas coordenações e/ou secretarias criadas nas IES para acompanhamento e avaliação da política de ação afirmativa. Em algumas universidades, esse trabalho é conduzido por pró-reitorias e secretarias e conta com a participação de egressos(as). Ainda no acompanhamento da política de ação afirmativa, é importante citar que muitos(as) dos(as) egressos(as) mencionam em seus currículos a participação e/ou coordenação dos trabalhos das bancas de heteroidentificação.

A participação efetiva de parte dos(as) egressos(as) nos processos de implementação e acompanhamento das políticas de ação afirmativa nas instituições em que atuam profissionalmente é um fator que merece aprofundamento, o que é necessário para melhores compreensão e caracterização desse ciclo, que compreende participação nos processos de formulação de políticas de ação afirmativa, execução da política e formação de novas gerações de ingressantes por egressos(as) dessas políticas.

Seria interessante também compreender se as experiências de gestão concentradas em cargos e/ ou espaços políticos de "gestão da diversidade étnico-racial" nas IES não seriam também uma estratégia de "acomodação" ou restrição dos espaços de gestão a determinados grupos.

Outra informação que buscamos sistematizar a partir dos currículos são as experiências de internacionalização dos(as) egressos(as). Nesse ponto, nove (16\%) egressos(as) registraram em seus currículos experiências internacionais - sete (12.5\%) no pós-doutorado e dois $(3.5 \%)$ de estágiossanduíche durante o mestrado e/ou doutorado, sendo um dos mestrados realizados integralmente em outro país. Na relação de países citados, constam Austrália, EUA, França, México e Portugal (Tabela 5).

Tabela 5. Trânsitos e experiências de internacionalização por países dos/as egressos/as do Concurso Negro e Educação

\begin{tabular}{cc} 
Instituição & País \\
\hline Flinders University & Austrália \\
\hline University of Wisconsin & EUA \\
\hline Department of Africana Studies - Brown University & EUA \\
\hline Georgia State University & França \\
\hline Université Paris-Ouest Nanterre la Défense & México \\
\hline Instituto Nacional de Antropología e História & México \\
\hline Universidade Nacional Autónoma de México & Portugal \\
\hline Universidade de Coimbra & Portugal
\end{tabular}


Aqui observamos um processo ainda inicial, que também precisa ser aprofundado a partir de outra pesquisa, como a produção acadêmica e parcerias/participação em projetos de pesquisa e barreiras linguísticas, informações que não foram analisadas neste trabalho. Compreender as motivações para os países de destino dos trânsitos realizados seria outra questão importante a ser explorada. Uma hipótese inicial é referente à influência da Fundação Ford nos grupos que se formaram no Brasil, o que provocaria trânsito privilegiado para os EUA.

\section{Considerações Finais}

As edições do Concurso Negro e Educação foram avaliadas e os dados, sistematizados em dois relatórios, intitulados "Concurso Negro e Educação: avaliação de processo" (DI PIERRO et al., 2004) e "Avaliação Concurso Negro e Educação: relatório final” (ROCHA; COUTO, 2007). Em síntese, as avaliações de processo e final indicam que o concurso significou novas possibilidades de inserção em espaços da academia para alguns(algumas) bolsistas.

No universo de 28 bolsistas que responderam sobre essa questão, 64\% se inseriram na pósgraduação depois da participação no concurso, 50\% em grupos de pesquisa, 25\% em NEAB e $14 \%$ em outros espaços da academia.

De acordo com Rocha e Couto, para integrantes das comissões e orientadores(as), o processo de supervisão dos projetos foi fundamental para o "amadurecimento intelectual" das produções acadêmicas dos(as) bolsistas, fazendo com que muitos(as) deles(as) dessem continuidade ao processo de formação acadêmica (ROCHA; COUTO, 2007, p. 35).

A dotação financeira destinada aos projetos viabilizou a aquisição de materiais bibliográficos, equipamentos tecnológicos e o deslocamento por espaços e eventos acadêmicos, inacessíveis até então, possibilitando assim, o crescimento individual e a consolidação desses(as) pesquisadores(as) no campo das relações étnico-raciais. Segundo Rocha e Couto, "a ampliação da rede de relações, as novas oportunidades profissionais e o compromisso com a reflexão sobre o tema são fatores que denotam os impactos do concurso na vida pessoal dos(as) bolsistas" (2007, p. 38-39).

Esta análise, a partir dos dados obtidos nos currículos da Plataforma Lattes, feita catorze anos após a finalização da última edição do concurso, permitiu a caracterização atualizada da inserção e da atuação profissional entre os(as) beneficiários(as) das edições do concurso. O resultado pode ser dimensionado pela inserção acadêmica e profissional dos(as) egressos(as) em IES e nas secretarias de educação municipais e estaduais.

A experiência do concurso pode contribuir para a discussão contemporânea das políticas de ação afirmativa, mostrando, por um lado, o impacto a longo prazo das políticas de ação afirmativa e, por outro lado, a percepção de que essa política precisa ultrapassar a garantia apenas do acesso. Ou seja, precisa ser acompanhada das condições de permanência e formação. As trajetórias dos(as) egressos(as) indicam que as políticas diferenciadoras são exitosas e produtoras de pesquisadores(as) inseridos(as) na academia e nos espaços de produção de conhecimento.

Os dados apresentados indicam o êxito da experiência realizada pelas quatro edições do Concurso Negro e Educação, bem como, a formação de uma rede de pesquisadores(as) em educação e relações étnico-raciais que poderia ser acionada para o desenvolvimento de ações e pesquisas sobre esse campo de estudo com abrangência nacional. 


\section{Contribuição das Autoras}

Problematização e Conceitualização: Rodrigues TC; Passos JC; Francchini F; Metodologia: Rodrigues TC; Passos JC; Francchini F; Análise: Rodrigues TC; Passos JC; Francchini F; Redação: Rodrigues TC; Passos JC; Francchini F.

\section{Notas}

1. Entre outros(as), citamos: Guerreiro Ramos, Clóvis Moura, Joel Rufino dos Santos, Virgínia Bicudo, Milton Santos, Lélia Gonzáles, Beatriz Nascimento, Kabengele Munanga, Iolanda de Oliveira, Petronilha Beatriz Gonçalves e Silva, Rachel de Oliveira, Henrique Cunha Júnior, Luis Alberto Oliveira Gonçalves, Ana Célia da Silva, Nilma Lino Gomes.

2. Estamos considerando como ação afirmativa um conjunto de políticas públicas e privadas de caráter compulsório, facultativo ou voluntário, cujo entendimento se amplia na medida em que não somente visa ao combate à discriminação racial, de gênero, por deficiência física e de origem nacional, mas também corrigir ou aplacar os efeitos presentes dessa discriminação praticada no passado (GOMES, 2005).

3. São núcleos criados no âmbito das universidades e que desenvolvem ensino, pesquisa e extensão voltados para as relações raciais.

4. Para saber mais, consultar: www.abpn.org.br

5. Criada em 1936 nos EUA como uma agência de fomento para apoio a projetos e instituições inovadoras. O escritório da fundação no Brasil foi aberto em 1962, no Rio de Janeiro, e suas primeiras doações foram a universidades públicas e instituições do governo para o fortalecimento de uma comunidade acadêmica no campo das Ciências Sociais. A história de atuação da fundação no Brasil pode ser consultada em Miceli (1993) e Brooke e Witoshynsky (2002).

6. A ANPEd é uma "entidade sem fins lucrativos que congrega programas de pós-graduação stricto sensu em educação, professores e estudantes vinculados a estes programas e demais pesquisadores da área. Tem por finalidade o desenvolvimento da ciência, da educação e da cultura, dentro dos princípios da participação democrática, da liberdade e da justiça social”. Para mais informações, conferir: https://www.anped.org.br

7. A Ação Educativa é uma organização social, sem fins lucrativos, fundada em 1994 em São Paulo. Desenvolve projetos nos campos da educação, da cultura e da juventude, na perspectiva dos direitos humanos. Para saber mais, acessar: https://acaoeducativa.org.br

8. O Programa Internacional de Bolsas, conhecido no Brasil como Programa Bolsa, faz parte de uma iniciativa da Fundação Ford, que financiou projetos relacionados com ação afirmativa em 22 países entre os anos de 2000 e 2012, totalizando 4.305 beneficiários. No Brasil, a coordenação do programa ficou sob responsabilidade da Profa. Dra. Fúlvia Rosemberg, pesquisadora da Fundação Carlos Chagas. Uma análise dos impactos do programa pode ser consultada em Artes e Mena-Chalco (2019).

9. Este primeiro trabalho de sistematização foi realizado com intuito de elaborar um projeto para uma nova edição do concurso, a ser discutido com o Ministério da Educação e a Secretaria Especial de Políticas de Promoção da Igualdade Racial (SEPPIR) a partir de um pedido feito pela então coordenação do GT 21 da ANPEd.

10. A Plataforma Lattes é um sistema virtual de currículos criado e mantido pelo Conselho Nacional de Desenvolvimento Científico e Tecnológico $(\mathrm{CNPq})$, pelo qual integra as bases de dados curriculares, grupos de pesquisa e instituições em um único sistema de informações, das áreas de Ciência e Tecnologia, atuando no Brasil.

11. A consulta aos currículos foi realizada no mês de março de 2021.

12. O percentual está definido a partir do total de 56 currículos localizados. 


\section{Referências}

ARTES, A.; MENA-CHALCO, J. P. O Programa de bolsas da Fundação Ford: 12 anos de atuação no Brasil. Educação \& Realidade, Porto Alegre, v. 44, n. 3, p. 1-22, 2019. https://doi.org/10.1590/2175-623681653

BROOKE, N.; WITOSHYNSKY, M. (orgs.). Os 40 anos da Fundação Ford no Brasil: uma parceria para mudança social. São Paulo/Rio de Janeiro: Editora da Universidade de São Paulo/Fundação Ford, 2002.

CARNEIRO, A. S. A construção do outro como Não-Ser como fundamento do Ser. 2005. 340 f. Tese (Doutorado em Educação) - Faculdade de Educação, Universidade de São Paulo, São Paulo, 2005.

CHAUÍ, M. Escritos sobre a universidade. São Paulo: Editora UNESP, 2001.

COLLINS, P. H. Pensamento feminista negro: conhecimento, consciência e a política do empoderamento. Tradução Jamile Pinheiro Dias. 1. ed. São Paulo: Boitempo, 2019.

DI PIERRO, M. C. et. al. Concurso Negro e educação: avaliação de processo. São Paulo: Ação Educativa/ Anped/Fundação Ford, 2004.

FIGUEIREDO, A.; GROSFOGUEL, R. Racismo à brasileira ou racismo sem racistas: colonialidade do poder e a negação do racismo no espaço universitário. Sociedade e Cultura, Goiânia, Goiânia, v. 12, n. 2, p. 223 234, jul./dez. 2009. https://doi.org/10.5216/sec.v12i2.9096

GAUDIO, E. S. Perspectiva negra decolonial: a insurgência de intelectuais negros/as em cursos de Pedagogia de Universidades do Sul do Brasil. 2021. 319 f. Tese (Doutorado em Educação) - Programa de Pós-graduação em Educação, Universidade Federal de Santa Catarina, Florianópolis, 2021.

GOMES, J. B. B. A recepção do instituto da ação afirmativa pelo direito constitucional brasileiro. In: SANTOS, S. A. Ações afirmativas e combate ao racismo nas Américas. Brasília, DF: Ministério da Educação/Secretaria de Educação Continuada/Alfabetização de Diversidade, 2005.

GOMES, N. L. Intelectuais negros e produção de conhecimento: algumas reflexões sobre a realidade brasileira. In: SANTOS, B. S.; MENESES, M. P. (orgs.). Epistemologias do Sul. São Paulo: Cortez, 2010.

GROSFOGUEL, R. A estrutura do conhecimento nas universidades ocidentalizadas: racismo/sexismo epistêmico e os quatro genocídios/epistemicídio do longo século XVI. Revista Sociedade e Estado, Brasília, DF, v. 31, n. 1, 2016. https://doi.org/10.1590/S0102-69922016000100003

HOOKS, b. Intelectuais negras. Estudos Feministas, Florianópolis, ano 3, n. 02/95, p. 464-478, 1995. https:// doi.org/10.1590/\%25x

MICELI, S. A Fundação Ford no Brasil. São Paulo: Sumaré/Fapesp, 1993.

MICELI, S. A fundação Ford e os cientistas sociais no Brasil, 1962-1972. História das Ciências Sociais no Brasil. São Paulo: Editora Sumaré/FAPESP, 1995. v. 2.

ROCHA, J. G.; COUTO, A. Avaliação Concurso Negro e Educação: relatório final. São Paulo: Ação Educativa/Assessoria Pesquisa e Informação, 2007.

ROSEMBERG, F.; ANDRADE, L. F. Ação afirmativa no Ensino Superior brasileiro: a tensão entre raça/etnia e gênero. Cadernos Pagu, Campinas, n. 31, p. 419-437, dez. 2008. https://doi.org/10.1590/ S0104-83332008000200018 
SANTOS, B. S. Pela mão de Alice: o social e o político na pós-modernidade. Porto: Edições Afrontamento, 1999.

SANTOS, B. S. A universidade no século XXI: para uma reforma democrática e emancipatória da universidade. São Paulo: Cortez Editora, 2004. (Coleção Questões da Nossa Época.)

SANTOS, S. A. A metamorfose de militantes negros em negros intelectuais. Revista Mosaico, Rio de Janeiro, v. 3, n. 5, 2011. https://doi.org/10.12660/rm.v3n5.2011.62800

SILVA, P. B. G. Negros na universidade e produção do conhecimento. In: SILVÉRIO, V.; SILVA, P. B. G. Entre a injustiça simbólica e a injustiça econômica. Brasília: INEP, 2003.

\section{Sobre as Autoras}

Tatiane Cosentino Rodrigues é formada em Pedagogia, mestre em Ciências Sociais, doutora em Educação e Professora Associada do Departamento de Teorias e Práticas Pedagógicas. Vice-coordenadora do Programa de Pós-Graduação em Educação da Universidade Federal de São Carlos (PPGE/UFSCar).

JoAna CÉLIA dos Passos é formada em Pedagogia e mestre e doutora em Educação pela Universidade Federal de Santa Catarina (UFSC). Linha de pesquisa: Formação de professores.

Flávia Francchini é licenciada plena em Pedagogia, mestre em Educação e doutoranda na mesma área pela Universidade Federal de São Carlos (UFSCar). Linha de pesquisa: Educação, Cultura e Subjetividade.

Recebido: 02 ago. 2021

Aceito: 09 out. 2021 